\title{
Thermophysical Properties of OSB Boards versus Equilibrium Moisture Content
}

\author{
Rastislav Igaz, ${ }^{\mathrm{a}}$ Luboš Krišt’ák, ${ }^{\mathrm{a}, *}$ Ivan Ružiak, ${ }^{\mathrm{a}}$ Milada Gajtanska, ${ }^{\mathrm{a}}$ and Martin Kučerka ${ }^{\mathrm{b}}$ \\ The basic thermophysical properties of oriented strand boards were \\ determined experimentally for use in humid conditions (OSB3) depending \\ on the moisture content. The dependency between the thermal \\ conductivity, thermal diffusivity, specific heat capacity, and the moisture \\ content in the range of $0 \%$ to $10 \%$, was examined. The non-stationary \\ extended dynamic plane source (EDPS) experimental method was used. \\ EDPS method was modified for anisotropic materials, i.e. with special \\ considerations of heat-loss effect occurring at the edge of measuring \\ samples, finite geometry of the sample and orthotropic thermal \\ conductivity, for use with anisotropic materials. The validity of the \\ experimental method was verified on polymethylmethacrylate (PMMA) \\ samples. The error rate of measurements conducted on PMMA samples \\ was less than $3 \%$, and for OSB3 boards it was less than $5.5 \%$. Based on \\ the experimental results, regression equations of the dependency \\ between the monitored properties and the moisture content were \\ determined. In the case of thermal conductivity and thermal capacity, the \\ determined dependencies showed a high correlation rate.
}

Keywords: Oriented strand board; Thermal conductivity; Specific heat capacity; Extended dynamic plane source method

Contact information: a: Department of Physics Electrical Engineering and Applied Mechanics, Faculty of Wood Science and Technology, T.G. Masaryka 24, 96001 Zvolen, Slovakia, b: Department of Technology, Faculty of Natural Sciences, Matej Bel University, Tajovského 40, 97401 Banská Bystrica, Slovakia; *Corresponding author: lubos.kristak123@gmail.com

\section{INTRODUCTION}

Oriented strand board (OSB) is a wood-based engineering material formed by adding adhesives between layers of wood strands by compressing the layers at a specific pressure and at various temperature profiles. Such OSB has good mechanical properties, and it is therefore also widely used in many load-bearing applications in construction, especially in wooden houses. The four grades of OSB are defined in terms of their mechanical performance and relative resistance to moisture: OSB1- General purpose boards and boards for interior fitments (including furniture) for use in dry conditions; OSB2- Load-bearing boards for use in dry conditions; OSB3- Load-bearing boards for use in humid conditions; and OSB4- Heavy-duty load-bearing boards for use in humid conditions (EN 300:2006). In comparison with plywood, the price of OSB boards is lower than that of plywood and the mechanical properties are almost the same.

The thermophysical properties of wood-based materials (solid woods, wood-based composites) have been widely studied in the literature (Siau 1984; TenWolde et al. 1988; Akoshima and Baba 2006; Aydin et al. 2014; Kminiak and Gaff 2015; Gaff et al. 2015; Igaz et al. 2015, 2016; Kvietková et al. 2015; Ružiak et al. 2017). The heat transfer in wood depends on the geometry of the wood sample, as well as porosity, moisture content 
(MC), and many other factors, e.g. wood after thermal modification (Košúth et al. 2012; Bekhta et al. 2015; Bekhta et al. 2016; Gaff et al. 2017a, 2017b). Because wood is a hygroscopic material, it mostly contains water in the form of bonded water or free water. The amount of water, which can be characterized by MC, has a profound effect on almost all properties of wood, including its thermal properties. Therefore, it is of great importance that the determined properties are given together with the actual MC (Adl-Zarrabi and Bostrőm 2004; Fidríková et al. 2013a, 2013b).

Studies have focused primarily on determining the effect of the density or MC on the specific heat capacity and thermal conductivity (Eckert and Goldstein 1976). There are various models of heat conductivity and specific heat capacity in the literature, but only two standardized techniques are available for accurate thermal testing of anisotropic materials such as wood and wood composites. There are two basic measurement techniques. The first group of measurement techniques is based on steady-state techniques, which works on establishing a temperature gradient over a known thickness of a sample and monitoring the heat flow from one side to the other. These techniques are best for materials with low or average thermal conductivities at moderate temperatures (Kol 2009a,b). The second group of measurement techniques are the transient (dynamic) techniques, which measure temperature $v s$. the time response of the sample when a signal is sent to the body to create heat. These methods can be used for thermal diffusivity and thermal conductivity measurements (Yesilata and Turgut 2007). These authors focused on a simple and inexpensive thermal testing technique. The measurements were based on the analysis of transient data. Another author, Al-Ajlan (2006), used a transient plane source (TPS) technique, also called the hot disk (HD), for measuring the thermal conductivity and diffusivity of materials. Al-Ajlan discovered that the thermal conductivity increases with increasing temperature, and decreases with increasing density over the temperature and density ranges. Adl-Zarrabi and Bostrőm (2004) investigated the thermal properties of Norway spruce, particleboard, and low-density fibreboard using the transient plane source method at different temperatures and at different MCs. Their measured values, as well as the measured effect of the temperature on the thermal properties were similar to previous studies (Adl-Zarrabi and Bostrőm 2004). Dupleix et al. (2012) measured the thermal properties of green wood by the TPS technique. They tested four wood species (Douglas fir, beech, birch, and spruce), and the results were compared with literature data and with data obtained by the laser flash method. They found a linear relationship between the thermal properties and density, and between the thermal properties and MC. They also found that the TPS technique is more universal than the transient hot wire (THW) or the transient hot strip (THS) methods, where the temperature measurement is localized to the thermocouple hot junction. Comparisons with proven older techniques, such as the steadystate and laser flash method, have demonstrated similar results, establishing that the TPS technique offers new opportunities for characterizing the thermal properties of wood, especially in the green state (Dupleix et al. 2012; Gaff et al. 2016; Kvasnová et al. 2016; Mitterpach and Stefko 2016). Li et al. (2013) proposed a modified step-wise transient method with special considerations of heat-loss effect occurring at the edge of measured samples, finite geometry of the sample, and orthotropic thermal conductivity. Transient heat transfer analysis of anisotropic material was used by Zhang et al. (2017). These authors used the Element-Free Galerkin (EFG) method. Their model can simplify the pretreatment for anisotropic material, which make the thermal conductivity executed by orthotropic factor and off-angle. Ohmura et al. (2001) estimated the mean thermal conductivity of anisotropic materials. They used the method of the plane directional 
thermal conductivity of fibrous insulations using the cyclic heat method and the transient hot-wire method.

TenWolde et al. (1988) have published a complex study of solid wood and wood composites thermal properties versus density, $\mathrm{MC}$, and temperature, but their publication did not involve data pertaining to OSB boards. Studies on thermal properties of OSB are scarce (especially specific heat capacity and thermal diffusivity), and comparison with other types of wood-based materials with a different construction and production technology as e.g. plywood, particleboard or fiberboard is not appropriate.

Authors Yapici et al. (2010) studied the dependence of urea formaldehyde adhesive concentration on the thermal conductivity of OSB boards. It is clear from the results that the thermal conductivity increases with the adhesive ratio, pressing time, and pressing pressure in the interval of conductivity between $0.129 \mathrm{~W} \cdot \mathrm{m}^{-1} \cdot \mathrm{K}^{-1}$ and $0.170 \mathrm{~W} \cdot \mathrm{m}^{-1} \cdot \mathrm{K}^{-1}$.

Thoemen et al. (2010) studied the dependence of thermal conductivity versus MC for the OSB3 board with a specific gravity of 0.562 and thickness of $18 \mathrm{~mm}$. The authors found the dependence of thermal conductivity $\lambda_{10}{ }^{\circ} \mathrm{C}$ versus $\mathrm{MC} \mathrm{MC}(\%)$ measured at $10{ }^{\circ} \mathrm{C}$ as shown by Eq. 1 .

$$
\lambda_{10{ }^{\circ} \mathrm{C}}=0.0959+0.00074 \cdot M C(\%)
$$

Many authors have also studied the dependence of thermal diffusivity versus MC. Most of these authors predict that the thermal diffusivity does not change significantly with the MC, and therefore the thermal diffusivity is only a function of wood material typ.

Other researchers (Rice and Redfern 2016) measured the dependence of specific heat capacity $c$ in $\mathrm{J} \cdot \mathrm{kg}^{-1} \cdot \mathrm{K}^{-1}$ on the $\mathrm{MC}(\%)$. They found the dependence for specific heat capacity $c$ in Eq. 2.

$$
c=1170.4+25.1 \cdot \mathrm{MC}
$$

Therefore, it is clear from previous literature that the thermophysical properties of OSB boards vary significantly with the manufacturing conditions, basic material selection (adhesive, OSB mat wood material), and many other parameters.

Kollmann and Malmquist (1956) studied the basic thermal conductivity of woodbased materials. With the help of the Kollmann model, it is possible to predict the thermal conductivity in the dry state (Kollmann and Malmquist 1956; Požgaj et al. 1997).

Perelygin (1965) and Kollmann and Côté (1968) studied the basic specific heat capacity in $\mathrm{J} \cdot \mathrm{kg}^{-1} \cdot \mathrm{K}^{-1}$. Perelygin (1965) describes the specific heat capacity in the dry state as the function of temperature, $T\left({ }^{\circ} \mathrm{C}\right)$ in Eq. 3,

$$
c_{0 \% M C}=1571.4+2.93 \cdot T
$$

Kollmann and Côté (1968) describe this dependence in Eq. 4,

$$
c_{0 \% M C}=1117.2+5.02 \cdot T
$$

Both studies compute the specific heat capacity dependence versus MC with the use of Eq. 5 (Požgaj et al. 1997),

$$
c_{M C}=\frac{c_{0 \% M C}+0.01 \cdot M C(\%) \cdot c_{w a t e r}}{1+0.01 \cdot M C(\%)}
$$

where $C_{0 \% \mathrm{MC}}$ is the specific heat capacity in the dry state $\left(\mathrm{J} \mathrm{kg}^{-1} \cdot \mathrm{K}^{-1}\right), \mathrm{MC}$ is the moisture content in the sample (\%), and $c_{\text {water }}$ is the specific heat capacity of water, $4186 \mathrm{~J} \cdot \mathrm{kg}^{-1} \cdot \mathrm{K}^{-1}$. 
From Eqs. 2 through 5, it is clear that the specific heat capacity varies significantly between the authors' models.

This paper focused on the material research of basic thermophysical properties of oriented strand boards for use in humid conditions (OSB3) depending on the moisture content. The non-stationary extended dynamic plane source (EDPS) experimental method was used. This method was primary designed for synthetic polymer materials research, another goal of our research was to find out applicability of this method for wood-based materials research.

\section{EXPERIMENTAL}

\section{Materials}

The input material for creating experimental samples was the commercially available OSB3 board (Bučina DDD, Slovakia, Zvolen) with a thickness of $10 \mathrm{~mm}$. The OSB board is produced as a three-layer wood composite made of oriented large-area chips. The input material for the production of OSB boards is mainly the Scots pine wood (Pinus sylvestris). The OSB boards are mostly used in construction for supporting and decorative elements in wooden constructions (walls, ceilings, basements), as deburring elements, or as packaging material for transport containers.

First, $100 \mathrm{~mm} \times 100 \mathrm{~mm} \times 10 \mathrm{~mm}$ experimental samples were cut from the OSB board. The sample sizes were based on the apparatus used, which is designed for researching samples of the aforementioned dimensions. The samples were not further mechanically modified. A total of 16 samples were prepared.

The experimental samples were then conditioned in an environmental chamber for 14 days $\left(20^{\circ} \mathrm{C}\right.$ and $\left.65 \%\right)$ to achieve an equilibrium $\mathrm{MC}$ throughout the material. The resulting average $\mathrm{MC}$ of the samples after individual conditioning cycles was approximately $10 \%, 8 \%$, and $5 \%$. Finally, the samples were oven-dried at $103{ }^{\circ} \mathrm{C} \pm 2{ }^{\circ} \mathrm{C}$ until they reached a constant weight. The sample MC was determined gravimetrically using a laboratory dryer (PREMED, Warszawa, Poland) and laboratory scale (OHAUS, Greifensee, Switzerland) according to ISO 13061-1 (2014). For each MC, the bulk density values of all samples were also determined.

After each conditioning cycle and after drying, the samples were subjected to an experiment to determine the thermophysical properties - thermal conductivity $(\lambda)$, thermal diffusivity $(a)$, and specific heat capacity $(c)$. Pairs needed for measurement on the extended dynamic plane source (EDPS) apparatus (Constantine the Philosopher University in Nitra, Nitra, Slovakia) were created from the samples. A series of five measurements was performed on each pair of samples. The resulting values of the monitored quantities were determined as the average of all measurements on the given pair of samples, and the variance and percent deviation values for the given pair were also determined. This ensured that the measurements were performed at all MCs in the range of $0 \%$ to $10 \%$.

To validate the results obtained by the EDPS method, reference test samples made of polymethylmethacrylate (PMMA) with a thickness of $10 \mathrm{~mm}$ were prepared. As with the OSB boards, the sample dimensions were $100 \mathrm{~mm} \times 100 \mathrm{~mm} \mathrm{x} 10 \mathrm{~mm}$. Polymethylmethacrylate has long been successfully used as a reference material for determining thermophysical properties because its properties exhibit low variance values.

For studying thermophysical properties, the authors measured the thermal conductivity and thermal diffusivity by the EDPS method at four different mean values of 
MC equal to $0 \%$, approximately $5 \%, 8 \%$, and $10 \%$. The $\mathrm{MC}$ in the samples was calculated by the gravimetric principle from the mass of the sample in dry state and the mass in nondry state.

The EDPS method needs two samples from the same material for determining the thermophysical properties. Therefore, the thermophysical properties for 4 different combinations at $0 \% \mathrm{MC}, 8$ different sample combinations at approximately $5 \%$ and $8 \%$, and 4 different combinations at $10 \% \mathrm{MC}$ were measured. The samples with an average value of $10 \% \mathrm{MC}$ were climatized at $20{ }^{\circ} \mathrm{C}$ and $65 \%$ relative humidity. All experimental measurements were performed at an ambient temperature of $T_{\text {ambient }}=21{ }^{\circ} \mathrm{C} \pm 1{ }^{\circ} \mathrm{C}$. All measurements were performed 5 times for each sample combination. The $\mathrm{MC}$ dependencies were calculated from the average values of the thermophysical properties for each sample combination and each average $\mathrm{MC}$ in the used sample combination. The average densities for the $0 \%, 5 \%, 8 \%$, and $10 \% \mathrm{MC}$ were equal to $\rho_{0 \%}=(541.45 \pm 16.52)$ $\mathrm{kg} \cdot \mathrm{m}^{-3}, \rho_{5 \%}=(559.77 \pm 18.78) \mathrm{kg} \cdot \mathrm{m}^{-3}, \rho_{8 \%}=(577.46 \pm 17.24) \mathrm{kg} \cdot \mathrm{m}^{-3}$, and $\rho_{10 \%}=(596.32 \pm$ 17.25) $\mathrm{kg} \cdot \mathrm{m}^{-3}$.

The average value of specific gravity calculated from all of the used samples was $S G=0.537 \pm 0.015$, from which the percentage error was $2.86 \%$. Therefore, the authors assumed that the specific gravity for all samples was 0.537 .

\section{Methods}

The measurements of the thermophysical properties of the samples were performed on an apparatus based on the EDPS method. This method is one of the basic transient methods listed in Table 1 (Malinarič 2004a; Božiková 2005; Božiková and Hlaváč 2014).

Table 1. Basic Transient Methods for Determining the Thermophysical Properties of Materials

\begin{tabular}{|c|c|c|c|}
\hline Heat Generation & Heat Flow & Measured Parameters & Name of Method \\
\hline Step-wise & Radial & $\lambda$ & Hot wire \\
\hline Pulse & 1-dimensional & $a, \lambda$ & Pulse transient \\
\hline Step-wise & 1-dimensional & $a, \lambda$ & Step-wise transient \\
\hline Step-wise & 3-dimensional & $a, \lambda$ & Hot disc \\
\hline Step-wise & 3-dimensional & $a, \lambda$ & Gustafsson probe \\
\hline Step-wise & 1-dimensional & $a, \lambda>2 W \cdot m^{-1} \cdot K^{-1}$ & DPS \\
\hline Step-wise & 1-dimensional & $a, \lambda<2 W \cdot m^{-1} \cdot K^{-1}$ & EDPS \\
\hline
\end{tabular}

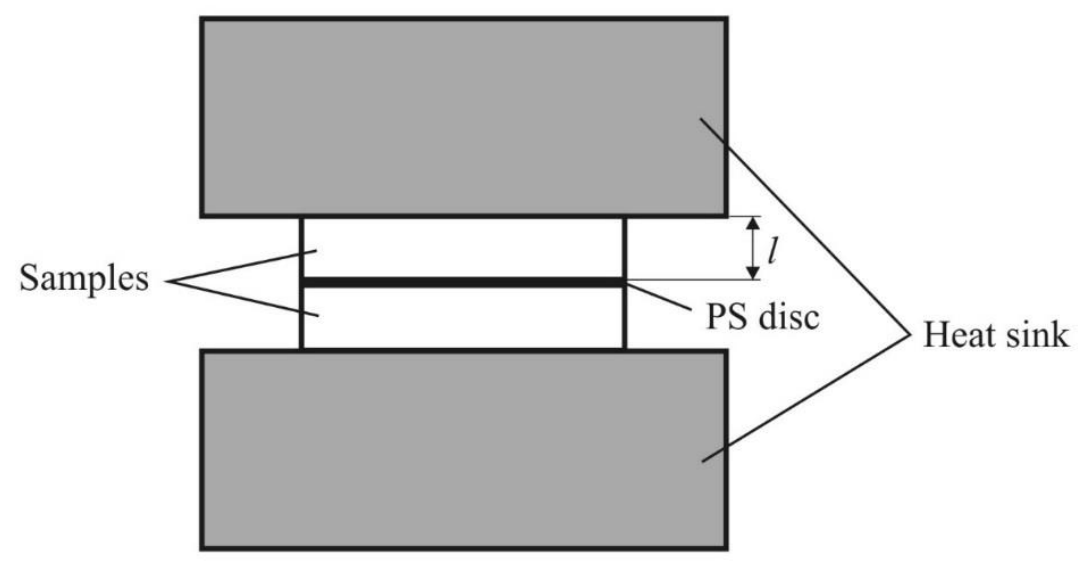

Fig. 1. Arrangement of samples and plane source (PS) disc 
In the EDPS method, two samples of the measured material are positioned between two large heat sinkers (made from duralumin in this case), and the electrical resistance is measured in the place between the measured samples, as shown in Fig. 1 (Malinaric 2004b).

The measured values of electrical resistance are converted to the temperature according to the linear dependence between the temperature and electrical resistance with the temperature coefficient of the electrical resistance of the PS disc, which was equal to $4.8 \cdot 10^{-3} \Omega . \mathrm{K}^{-1}$ in this case.

The modified EDPS method with special considerations of heat-loss effect occurring at the edge of measuring samples, finite geometry of the sample and orthotropic thermal conductivity can be used for anisotropic materials. These variables must be considered in the theoretical temperature function in Eq. 6 (Malinarič 2004b),

$$
T(t)=\frac{q l}{\lambda} \cdot \sqrt{\frac{t}{\pi \cdot \theta}} \cdot\left(1+2 \cdot \sqrt{\pi} \cdot \sum_{n=1}^{\infty} \beta^{n} \cdot \operatorname{ierfc}\left(n \cdot \sqrt{\frac{\theta}{t}}\right)\right)
$$

where $q$ is the heat current density $\left(\mathrm{W} \cdot \mathrm{m}^{-2}\right), \lambda$ is the thermal conductivity $\left(\mathrm{W} \cdot \mathrm{m}^{-1} \cdot \mathrm{K}^{-1}\right.$ ), and the parameter $\beta$ describes heat sink imperfection (-1.000 for ideal heat sink), which was calculated from known thermal properties of reference material PMMA with similar geometry (Malinarič 2004b). Ierfc is the error function integral, which was computed from a parametric fitting procedure between natural logarithm of measured temperature function and linear dependence in the shape of $\ln (T)=c_{0}+c_{1} .(t / \theta)$ with regard to anisotropic wood based samples. Sensitivity coefficients were analysed using (Malinarič, 2003, Malinarič, $2004 b$ ). Parameter $\theta$ is called the characteristic time (s), and it is bonded with thermal diffusivity $a$ and an average thickness of used samples $l$ with Eq. 7.

$$
\theta=\frac{l^{2}}{a}
$$

The values of thermal conductivity $(\lambda)$ and the characteristic time $(\theta)$ are determined by the fitting procedure (Malinarič 2007; Koštial et al. 2010). The thermal diffusivity was then calculated from the known average thickness value of sample $A$, and the specific heat capacity was finally calculated according to the well-known formula between thermophysical properties Eq. 8,

$$
\lambda=\rho \cdot a \cdot c
$$

where $\rho$ is the average density of used samples $\left(\mathrm{kg} \cdot \mathrm{m}^{-3}\right)$ at the known average MC (\%).

Finally, the specific gravity of the material was calculated from the known density value with the MC (\%) according to Eq. 9.

$$
S G=\frac{\rho_{M C}}{(1+0.01 \cdot M C(\%)) \cdot 1000}
$$




\section{RESULTS AND DISCUSSION}

All measurements were performed using EDPS method with electrical parameters $\mathrm{I}=1.0 \mathrm{~A}, \mathrm{U}=7.0 \mathrm{~V}$ during 300 seconds. With these settings, a temperature increase of about $15{ }^{\circ} \mathrm{C}$ was obtained. Ambient temperature during all measurements was $21 \pm 1{ }^{\circ} \mathrm{C}$.

The authors will present the measured results of the thermophysical properties of OSB board samples and the results for the PMMA reference sample.

The PMMA sample was measured 10 times to obtain the measurement reproducibility. The measured values of thermal conductivity $(\lambda)$, thermal diffusivity (a), and specific heat capacity $(c)$ are listed in Table 2.

Table 2. Thermophysical Properties of the PMMA Reference Material versus Literature Values

\begin{tabular}{|c|c|c|c|}
\hline Property & Experimental Values & Table Values & Percentage Error (\%) \\
\hline$\lambda\left(\mathrm{W} \cdot \mathrm{m}^{-1} \cdot \mathrm{K}^{-1}\right)$ & $0.201 \pm 0.002$ & 0.19 to 0.24 & 1.00 \\
\hline$a\left(\mathrm{~mm}^{2} \cdot \mathrm{s}^{-1}\right)$ & $0.121 \pm 0.003$ & 0.109 to 0.143 & 2.48 \\
\hline$c\left(\mathrm{~J}_{\mathrm{kg}} \cdot \mathrm{K}^{-1} \cdot \mathrm{K}^{-1}\right)$ & $1452.5 \pm 25.1$ & 1460 to 1470 & 1.58 \\
\hline
\end{tabular}

It is clear from Table 2 that the measured values of PMMA were in very good agreement with the table values, and that the measuring error rate for all three basic thermophysical properties did not exceed $3 \%$.

Table 3 presents the values of thermal diffusivity $a$ for OSB board samples along with the MC values. All values in Table 3 were considered for determining the effect of the MC on the thermal diffusivity.

Table 3. Values of thermal diffusivity a of used OSB Board Samples

\begin{tabular}{|c|c|}
\hline $\mathbf{M C}(\%)$ & $\boldsymbol{a}\left(\mathbf{m m}^{\mathbf{2}} \mathbf{s}^{-1}\right)$ \\
\hline 0.00 & $0.121 \pm 0.003$ \\
\hline 4.86 & $0.124 \pm 0.005$ \\
\hline 7.83 & $0.123 \pm 0.003$ \\
\hline 10.14 & $0.124 \pm 0.005$ \\
\hline
\end{tabular}

From Table 3 it can be seen that the thermal diffusivity $a$ was not noticeably affected by the MC in the material. Therefore, based on the research results we assumed that thermal diffusivity did not noticeably change with the MC. Furthermore, data on thermal diffusivity of wood are scarce (Suleiman et al. 1999).

Table 4 presents the values of thermal conductivity, thermal diffusivity, and the specific heat capacity for OSB board samples, along with the MC. The values for the dry state were averaged because the MC in the dry samples was assumed $0 \%$ in all of the samples. All of the values in Table 4 were considered for determining the effect of the MC on the thermophysical properties. From Table 4 it can be seen that the measuring percentage error for all investigated samples did not exceed $5.5 \%$. The average percentage error for the thermophysical properties did not exceed 4\%, which meant excellent repeatability according to the material type. Figure 2 presents both the experimental and predicted dependence of the thermal conductivity versus MC, and Fig. 3 illustrates the same dependence for the specific heat capacity one. 
Table 4. Values for the MC Dependence on the Thermophysical Properties of used OSB Board Samples

\begin{tabular}{|c|c|c|c|}
\hline MC (\%) & $a\left(\mathrm{~mm}^{2} \cdot \mathrm{s}^{-1}\right)$ & $\lambda\left(\mathrm{W} \cdot \mathrm{m}^{-1} \cdot \mathrm{K}^{-1}\right)$ & $c\left(\mathrm{~J} \cdot \mathrm{kg}^{-1} \cdot \mathrm{K}^{-1}\right)$ \\
\hline 0.00 & $0.120 \pm 0.002$ & $0.083 \pm 0.001$ & $1287.6 \pm 17.9$ \\
\hline 0.00 & $0.120 \pm 0.003$ & $0.083 \pm 0.002$ & $1326.6 \pm 28.1$ \\
\hline 0.00 & $0.121 \pm 0.004$ & $0.086 \pm 0.003$ & $1275.8 \pm 22.9$ \\
\hline 0.00 & $0.121 \pm 0.003$ & $0.086 \pm 0.003$ & $1282.5 \pm 45.9$ \\
\hline 4.79 & $0.122 \pm 0.004$ & $0.096 \pm 0.005$ & $1411.9 \pm 41.3$ \\
\hline 4.87 & $0.126 \pm 0.004$ & $0.096 \pm 0.003$ & $1405.9 \pm 64.4$ \\
\hline 4.78 & $0.116 \pm 0.005$ & $0.095 \pm 0.003$ & $1446.3 \pm 30.3$ \\
\hline 5.00 & $0.126 \pm 0.003$ & $0.096 \pm 0.004$ & $1435.2 \pm 57.3$ \\
\hline 4.85 & $0.127 \pm 0.002$ & $0.101 \pm 0.005$ & $1372.9 \pm 48.7$ \\
\hline 4.90 & $0.121 \pm 0.003$ & $0.097 \pm 0.003$ & $1376.9 \pm 18.9$ \\
\hline 7.97 & $0.122 \pm 0.002$ & $0.111 \pm 0.003$ & $1578.1 \pm 25.1$ \\
\hline 7.83 & $0.123 \pm 0.001$ & $0.107 \pm 0.003$ & $1561.4 \pm 33.5$ \\
\hline 7.82 & $0.121 \pm 0.002$ & $0.111 \pm 0.006$ & $1565.6 \pm 58.6$ \\
\hline 7.93 & $0.127 \pm 0.002$ & $0.106 \pm 0.002$ & $1523.7 \pm 16.7$ \\
\hline 7.81 & $0.124 \pm 0.005$ & $0.110 \pm 0.004$ & $1494.4 \pm 37.7$ \\
\hline 7.62 & $0.119 \pm 0.003$ & $0.109 \pm 0.005$ & $1536.3 \pm 33.5$ \\
\hline 7.76 & $0.123 \pm 0.004$ & $0.111 \pm 0.004$ & $1477.7 \pm 12.6$ \\
\hline 7.89 & $0.122 \pm 0.002$ & $0.111 \pm 0.002$ & $1578.1 \pm 67.0$ \\
\hline 10.17 & $0.124 \pm 0.003$ & $0.117 \pm 0.004$ & $1615.8 \pm 41.9$ \\
\hline 10.39 & $0.128 \pm 0.003$ & $0.117 \pm 0.003$ & $1594.9 \pm 37.7$ \\
\hline 10.03 & $0.121 \pm 0.004$ & $0.118 \pm 0.004$ & $1599.1 \pm 41.9$ \\
\hline 9.98 & $0.123 \pm 0.005$ & $0.120 \pm 0.003$ & $1603.2 \pm 50.2$ \\
\hline
\end{tabular}

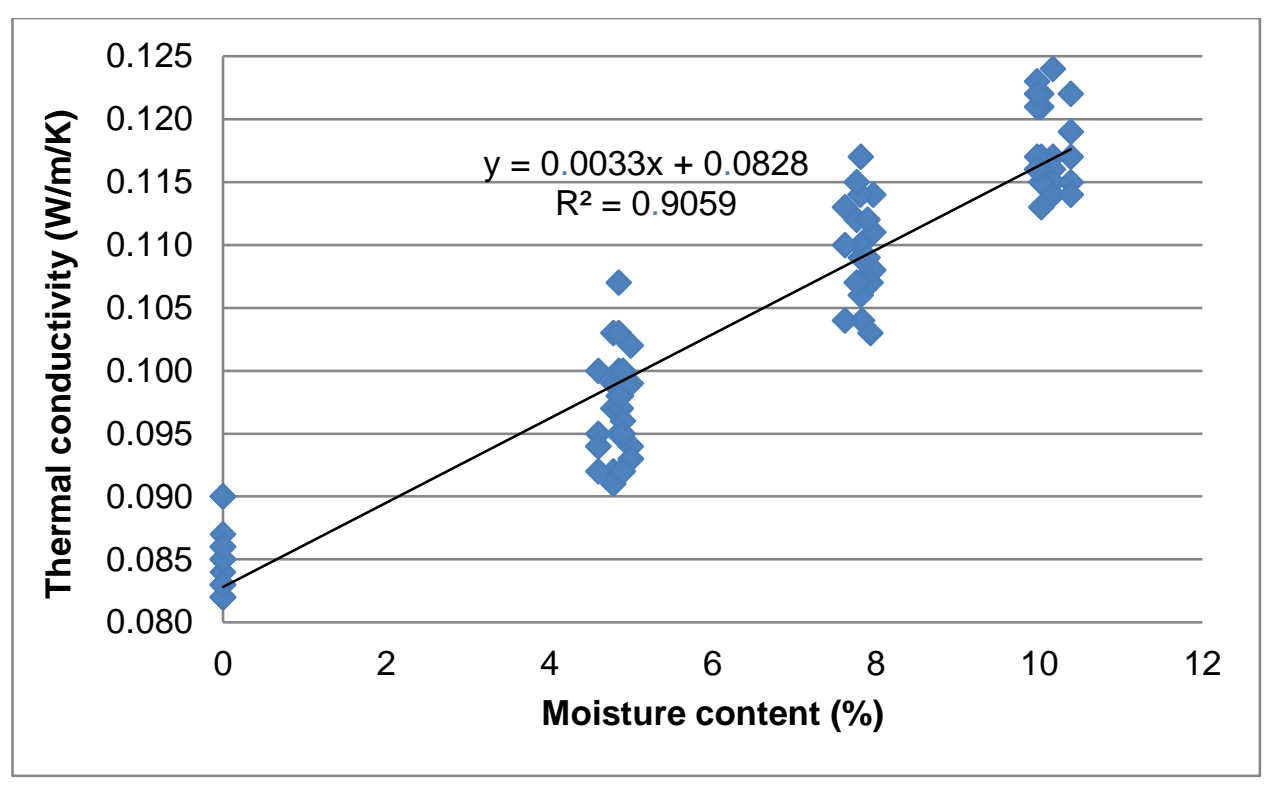

Fig. 2. Effect of the MC on thermal conductivity 


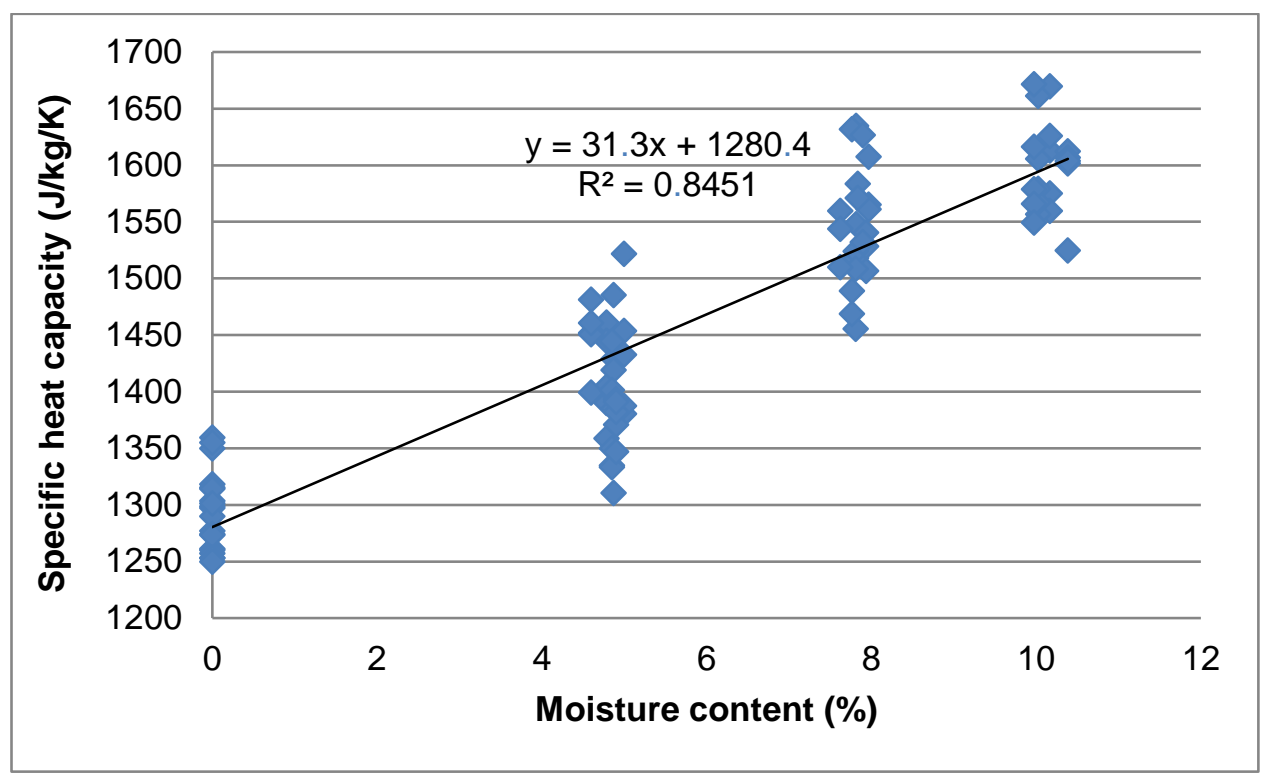

Fig. 3. Effect of the MC on the specific heat capacity

In the next part, the authors discuss the dependence of the MC on thermophysical properties. Table 5 presents the coefficient of determination $\left(\mathrm{R}^{2}\right)$, root mean square error (RMSE) for thermal conductivity, thermal diffusivity, and specific heat capacity versus MC.

Table 5. Statistical Parameters for the Dependence of Thermophysical Properties on the MC

\begin{tabular}{|c|c|c|c|}
\hline & $\boldsymbol{a}\left(\mathbf{m m}^{2} \cdot \mathbf{s}^{-1}\right)$ & $\boldsymbol{\lambda}\left(\mathbf{W} \cdot \mathbf{m}^{-1} \cdot \mathbf{K}^{-1}\right)$ & $\boldsymbol{c}\left(\mathbf{J} . \mathbf{k g}^{-1} \cdot \mathbf{K}^{-1}\right)$ \\
\hline$R^{2}(-)$ & 0.0724 & 0.9059 & 0.8451 \\
\hline RMSE & 0.0004 & 0.0004 & 4.961 \\
\hline
\end{tabular}

Tables 3 and 5 shows that the MC did not have a substantial effect on the thermal diffusivity.

From the coefficient of determination for thermal conductivity and specific heat capacity, it is clear that the effect of the MC on both thermal conductivity and specific heat capacity can be found in a linear form. The dependence of the thermal conductivity versus MC can be described by the formula $\lambda=0.0828+0.0033 \mathrm{MC}$. The dependence of specific heat capacity is given by the formula $c=1280.4+31.3 \mathrm{MC}$.

The measured dependence of thermal conductivity versus $\mathrm{MC}$ is different according to authors Thoemen et al. (2010). This difference is probably due to the different type of basic material used by the authors (Thoemen et al. 2010). According to the very high coefficient of correlation and very low values of RMSE and percentage error, the authors assume that the predicted dependence, as shown in Fig. 2, was correct.

The results revealed that the measured specific heat capacity corresponded with the reference values from authors Rice and Redfern (2016). The cited authors published the first study about specific heat capacity of OSB boards. Differences in the slope of specific heat capacity versus MC is approximately about $10 \%$. Rice and Redfern predicted the specific heat capacity in the oven-dry state as equal to $1170 \mathrm{~J} \cdot \mathrm{kg}^{-1} \cdot \mathrm{K}^{-1}$ while the present 
prediction is equal to $1280 \mathrm{~J} \cdot \mathrm{kg}^{-1} \cdot \mathrm{K}^{-1}$. Differences in the oven-dry specific heat capacity can be caused by the different base of wood material.

\section{CONCLUSIONS}

The EDPS method was mainly proposed for study of thermophysical properties of low conductive polymeric materials, which mostly are not hygroscopic and have relative higher order of homogeneity. In the present work it was shown that this transient method can be successfully applied also on the wood based composite materials. For proper use of this method it is very important to perform precise analysis of heat sink imperfection and error function values with special consideration of heat-loss effect occurring at the edge of measuring samples, finite geometry of the sample, and orthotropic thermal conductivity. The percentage error for this OSB material was lower than 5.5\%, which is acceptable for wood composite material.

This article presents measured data of thermal diffusivity across a range of moisture content values for the OSB boards. We find out, that the thermal diffusivity $a$ was not noticeably affected by the MC in the material. Therefore, based on the research results we assumed that thermal diffusivity did not noticeably change with the MC.

Based on the measured data sets of thermal conductivity and the $\mathrm{MC}$, an equation of dependence on the coefficient of thermal conductivity was determined.

For the dependency between the specific heat capacity and the $\mathrm{MC}$, an equation of dependence on the coefficient of specific heat capacity was determined.

According to the low percentage error of thermal conductivity and specific heat capacity measurements these formulas can be applied for the prediction of thermal conductivity vs. MC and specific heat capacity vs. MC of OSB boards made of domestic wood processed in central Europe.

Statistical parameters $\mathrm{R}^{2}$ and RMSE also confirmed the validity of obtained formulas for thermal conductivity and specific heat capacity vs. MC.

\section{ACKNOWLEDGMENTS}

This research was supported by VEGA1/0213/15, ITMS 23210120024, and the Slovak Research and Development Agency under the contract No. APVV-14-0506 "ENPROMO".

\section{REFERENCES CITED}

Adl-Zarrabi, B., and Bostrőm, L. (2004). "Determination of thermal properties of wood and wood based products by using transient plane source," in: Proceedings of the 8th World Conference on Timber Engineering, WCTE 2004, Lahti, Finland, pp. 604

Akoshima, M., and Baba, T. (2006). "Study on a thermal-diffusivity standard for laser flash method measurements," International Journal of Thermophysics 27(4), 11891203. DOI: $10.1007 / \mathrm{s} 10765-006-0091-9$ 
Al-Ajlan, S. A. (2006). "Measurements of thermal properties of insulation materials by using transient plane source technique," Applied Thermal Engineering 26(17-18), 2184-2191. DOI: 10.1016/j.applthermaleng.2006.04.006

Aydin, I., Demirkir, C., Colak, S., Colakoglu, G., and Öztürk, H. (2014). "Effect of wood species and adhesive types on thermal conductivity of plywood," in: 25 th

International Scientific Conference New Materials and Technologies in the Function of Wooden Products, Zagreb, Croatia, pp. 59-62.

Bekhta, P., Mamoňová, M., Sedliačik, J., and Novák, I. (2016). “Anatomical study of short-term thermos-mechanically densified alder wood with low MC," European Journal of Wood and Wood Products 74(5), 643-652. DOI: 10.1007/s00107-0161033-2

Bekhta, P., Proszyk, S., Krystofiak, T., Sedliačik, J., Novak, I., and Mamoňová, M. (2015). "Effects of short-term thermomechanical densification on the structure and properties of wood veneers," Wood Material Science and Engineering 12(1), 40-54. DOI: $10.1080 / 17480272.2015 .1009488$

Božiková, M. (2005). "Thermophysical parameters of chosen granular samples," International Agrophysics 19(3), 203-207.

Božiková, M., and Hlaváč, P. (2014). "Transient method and their usage for flour thermophysical parameters measurement," Advanced Materials Research 1059, 7582. DOI: $10.4028 / w w w . s c i e n t i f i c . n e t / A M R .1059 .75$

Dupleix, A., Kusiak, A., Hughes, M., and Rossi, F. (2012). "Measuring the thermal properties of green wood by the transient plane source (TPS) technique," International Journal of the Biology, Chemistry, Physics, and Technology of Wood 64(4), 1-9. DOI: 10.1515/hf-2012-0125

Eckert, E. R. G., and Goldstein, R. J. (1976). Measurements in Heat Transfer, Hemisphere Publishing, Washington, D.C.

EN 300:2006. "Oriented Strand Boards (OSB) - Definitions, classification and specifications," APA Individual standards. Online: http://apawoodeurope.org/official-guidelines/european-standards/individual-standards/en-300/

Fidríková, D., Greif, V., Dieška, P., Štofanik, V., Kubičár, L., and Vlčko, J. (2013a). "Monitoring of the temperature-moisture regime in St. Martin's Cathedral tower in Bratislava," Environmental Earth Sciences 69(4), 1481-1489. DOI: 10.1007/s12665012-2160-7

Fidríková, D., Vretenár, V., Šimková, I., Greif, V., Vlčko, J., Dieška, P., and Kubičár, L. (2013b). "Sensor for monitoring the moisture in porous materials," International Journal of Thermophysics 34(10), 1918-1929. DOI: 10.1007/s10765-013-1493-0

Gaff, M., Babiak, M., Vokatý, V., Gašparík, M., and Ruman, D. (2017a). "Bendability characteristics of hardwood lamellae in elastic region," Composites Part B: Engineering 116, 61-75. DOI: 10.1016/j.compositesb.2016.12.058

Gaff, M., Gašparík, M., Babiak, M., and Vokatý, V. (2017b). "Bendability characteristics of wood lamellae in plastic region," Composite Structures 163, 410-422. DOI: 10.1016/j.compstruct.2016.12.052

Gaff, M., Gašparík, M., Borůvka, V., and Haviarová, E. (2015). "Stress simulation in layered wood-based materials under mechanical loading," Materials and Design 87, 1065-1071. DOI: 10.1016/j.matdes.2015.08.128

Gaff, M., Vokatý, V., Babiak, M., and Bal, B. C. (2016). "Coefficient of wood bendability as a function of selected factors," Construction and Building Materials 126, 632-640. DOI: 10.1016/j.conbuildmat.2016.09.085 
Igaz, R., Krišt’ák, L., Ružiak, I., Réh, R., and Danihelová, Z. (2016). "Heat transfer during pressing of 3D moulded veneer plywood composite materials," Key Engineering Materials 688(4), 131-137. DOI: 10.4028/www.scientific.net/KEM.688.131

Igaz, R., Ružiak, I., Krišt’ák, L., Réh, R., Iždinský, J., and Šiagiová, P. (2015). "Optimization of pressing parameters of crosswise bonded timber formwork sheets," Acta Facultatis Xylologiae Zvolen 57(1), 83-88.

ISO 13061-1 (2014). "Physical and mechanical properties of wood. Test methods for small clear wood specimens. Part 1: Determination of MC for physical and mechanical tests," Internat. Organization for Standardization, Geneva, Switzerland.

Kminiak, R., and Gaff, M. (2015). "Roughness of surface created by transversal sawing of spruce, beech, and oak wood," BioResources 10(2), 2873-2887. DOI: 10.15376/biores.10.2.2873-2887

Kol, H. Ş. (2009a). "The transverse thermal conductivity coefficients of some hardwood species grown in Turkey," Forest Products Journal 59(10), 58-63. DOI: 10.13073/0015-7473-59.10.58

Kol, H. Ş. (2009b). "Effect of some chemicals on thermal conductivity of impregnated laminated veneer lumbers bonded with polyvinyl acetate and melamine-formaldehyde adhesives," Drying Technology 27(9), 1010-1016. DOI: 10.1080/07373930902905092

Kollmann, F., and Côté, W.A. (1968). Principles of Wood Science and Technology, Springer-Verlag, Berlin, Germany.

Kollmann, F., and Malmquist, L. (1956). "Über die Wärmeleitzahl von Holz und Holzwerkstoffen / About thermal conductivity coefficient of wood and wooden based materials," Holz als Roh und Werkstoff 14(6), 201-204. DOI: 10.1007/BF02615595

Koštial, P., Ružiak, I., Jonšta, Z., Kopal, I., Hrehuš, R., Kršková, J. (2010). "Experimental method for complex thermo-mechanical material analysis," International J. Thermophysics 31(3), 630-636. DOI: 10.1007/s10765-010-0745-5

Košúth, S., Němec, M., and Petrík, J. (2012). "Physical-acoustical characteristics of thermowood in relation to the manufacture of musical instrument," Akustika 17(1), 18-21.

Kvasnová, P., Novák, D., and Novák, V. (2016). “Chemical analysis and mechanical properties of selected safety components of lifts," Manufacturing Technology 16(1), 149-154.

Kvietková, M., Gaff, M., Gašparík, M., Kaplan, L., and Barcík, Š. (2015). "Surface quality of milled birch wood after thermal treatment at various temperatures," BioResources 10(4), 6512-6521. DOI: 10.15376/biores.10.4.6512-6521.

Li, X., Yue, K., and Zhang, X. (2013). "A modified step-wise transient method for measuring the thermal conductivity of anisotropic materials," in: ASME 2013 International Mechanical Engineering Congress and Exposition, San Diego, California, DOI: 10.1115/IMCE2013-64624.

Malinarič, S. (2003). "Sensitivity coefficients analysis in EDPS method," in: Proceedings of the Thermophysics 2003 Conference, Nitra, Slovak Republic, pp.12-17.

Malinarič, S. (2004a). "Contribution to the extended dynamic plane source method," in: Proceedings of the Thermophysics 2004 Conf., Nitra, Slovak Republic, pp. 120-125.

Malinarič, S. (2004b). "Contribution to the sensitivity coefficients analysis in the extended dynamic plane source (EDPS) method," International Journal of Thermophysics 25(6), 1913-1919. DOI: 10.1007/s10765-004-7745-2 
Malinarič, S. (2007). "Uncertainty analysis of thermophysical property measurements of solids using dynamic methods," International Journal of Thermophysics 28(1), 20-32. DOI: $10.1007 / \mathrm{s} 10765-006-0134-2$

Mitterpach, J., and Štefko, J. (2016). "An environmental impact of a wooden and brick house by the LCA method," Key Engineering Materials 688(4), 204-209. DOI: 10.4028/www.scientific.net/KEM.688.204

Ohmura, T., Tsuboi, M., and Tomimura, T. (2001). "Estimation of the mean thermal conductivity of anisotropic materials," International Journal of Thermophysics, 23(3), pp. 843-853, DOI: 10.1023/A:101542370.

Perelygin, L. M. (1965). Náuka o dreve [Woodworking], SVTL, Bratislava, Slovakia.

Požgaj, A., Chovanec, D., Kurjatko, S., and Babiak, M. (1997). "Štruktúra a vlastnosti dreva [Sturcture and Properties of Wood], Príroda, Bratislava, Slovakia.

Rice, R. W., and Redfern, I. (2016). "Heat capacity and its variation with MC for plywood and oriented strand board sheathing produced by North American mills," Forest Products Journal 66(7/8), 413-418. DOI: 10.13073/FPJ-D-15-00062

Ružiak, I., Igaz, R., Krišták, L., Réh, R., Mitterpach, J., Očkajová, A., and Kučerka, M. (2017). "Influence of urea-formaldehyde adhesive modification with beech bark on chosen properties of plywood," BioResources 12(2), 3250-3264. DOI: 10.15376/biores.12.2.3250-3264

Siau, J. F. (1984). Transport Processes in Wood, Springer Series in Wood Science, Springer-Verlag, DOI: 10.1007/978-3-642-69213-0.

Suleiman, B. M., Larfeldt, J., Leckner, B., and Gustavsson, M. (1999). "Thermal conductivity and diffusivity of wood" Wood science and Technology 33, 465-473, Springer-Verlag

TenWolde, A., McNatt, J. D., and Krahn, L. (1988). "Thermal properties of wood and wood panel products for use in buildings", INC. DOE/USDA-21697/1, USDA Forest Service, Madison, USA.

Thoemen, H., Irle, M., and Sernek, M. (2010). Wood-Based Panels, Brunel University Press, London, England.

Yapici, F., Gündüz, G., and Özçifçi, A. (2010). "The effects of some production factors on thermal conductivity of oriented strand board," Technology 13(2), 65-70, ISSN 2339-5478.

Yesilata, B., and Turgut, P. (2007). "A simple dynamic measurement technique for comparing thermal insulation performances of anisotropic building material," Energy and Buildings 39(9), 1027-1034. DOI: 10.1016/j.enbuild.2006.11.007

Zhang, H., Li, Y., and Tao, W. (2017). "Theoretical accuracy of anisotropic thermal conductivity determined by transient plane source method," International Journal of Heat and Mass Transfer 108(2017), 1634-1644, DOI: 10.1016/j.ljheatmasstransfer.2017.01.025.

Zhang. J., Zhou, G., Gong, S., and Wang, S. (2017). "Transient heat transfer analysis of anisotropic material by using Element-Free Galerkin method," International Communications in Heat and Mass Transfer 84(5), pp. 134-143, DOI: 10.1016/j.icheatmasstransfer.2017.04.003.

Article submitted: June 7, 2017; Peer review completed: September 9, 2017; Revised version received and accepted: September 12, 2017; Published: September 15, 2017. DOI: $10.15376 /$ biores. 12.4.8106-8118 